\title{
Larva de quinto estádio e pupa de Dasyophthalma rusina rusina (Godart) (Lepidoptera, Nymphalidae, Brassolinae) ${ }^{1}$
}

\author{
Mirna M. Casagrande ${ }^{2}$ \\ Olaf H.H. Mielke ${ }^{2}$
}

\begin{abstract}
Fifth larval instar and pupa of Dasyophthalma rusina rusina (Godart). (Lepidoptera, Nymphalidae, Brassolinae). Description of the fifth larval instar and pupa of Dasyophthalma rusina rusina (Godart, [1824]) from material reared in southern Brasil are described and illustrated. The larva feed on leaves of Geonoma schottiana Martius (Arecaceae).
\end{abstract}

KEY WORDS. Brassolinae, Dasyophthalma rusina rusina, immature stages, hostplant

As espécies do gênero Dasyophthalma Westwood, 1851, quando comparadas com as espécies de outros gêneros da subfamília são classificadas como de médio porte, isto é, não tão grandes como as de Caligo Hübner, [1819] e nem tão pequenas como as de Narope Doubleday, [1849]. São habitantes das florestas subtropicais na costa leste e sul do Brasil. O vôo é lento e nos horários de sol intenso diferente portanto da grande maioria dos gêneros de Brassolinae que possuem hábitos crepusculares.

Neste trabalho descreve-se e ilustra-se a larva de quinto estádio e a pupa e, ilustra-se o adulto de Dasyophthalma rusina rusina provenientes de Rio Natal, São Bento do Sul, Santa Catarina, Brasil, 500m. A nomenclatura das áreas do corpo da larva estão descritas conforme definidas em PETERSON (1962) e da pupa como em CASAGRANDE (1979).

\section{Larva de quinto estádio (Figs 1-5)}

Cabeça de forma quadrangular com escolos, de coloração geral verde com faixas em verde mais escuro, que partem da região ocelar divergindo até a base dos escolos e na fronte acompanhando a sutura epicranial até o vértice. Cerdas claras, distribuídas por todas as áreas inclusive nos escolos. Na região posterior, os três pares de escolos: dorsais, látero-dorsais e látero-ventrais, direcionados para o tórax e não para cima como em Caligo. São verdes passando a ferrugíneos. Entre a base das mandíbulas e os ocelos, um tufo de cerdas claras e outro de cerdas escuras, projetados anteriormente.

Tórax e abdome pubescente, de coloração geral verde com faixas e estrias longitudinais em diferentes tons de castanho, amarelo e verde escuro. As cerdas são simples, claras como as da cabeça, sobre pináculos branco leitoso. Faixa mediana dorsal, desde o protórax até a base das projeções da placa suranal, em amarelo cítrico, interrompida nos segmentos abdominais três e quatro, por mancha branco leitosa,

1) Contribuição número 1182 do Departamento de Zoologia, Universidade Federal do Paraná.

2) Departamento de Zoologia, Universidade Federal do Paraná. Caixa Postal 19020, 81531-990 Curitiba, Paraná, Brasil. Bolsista do CNPq. 

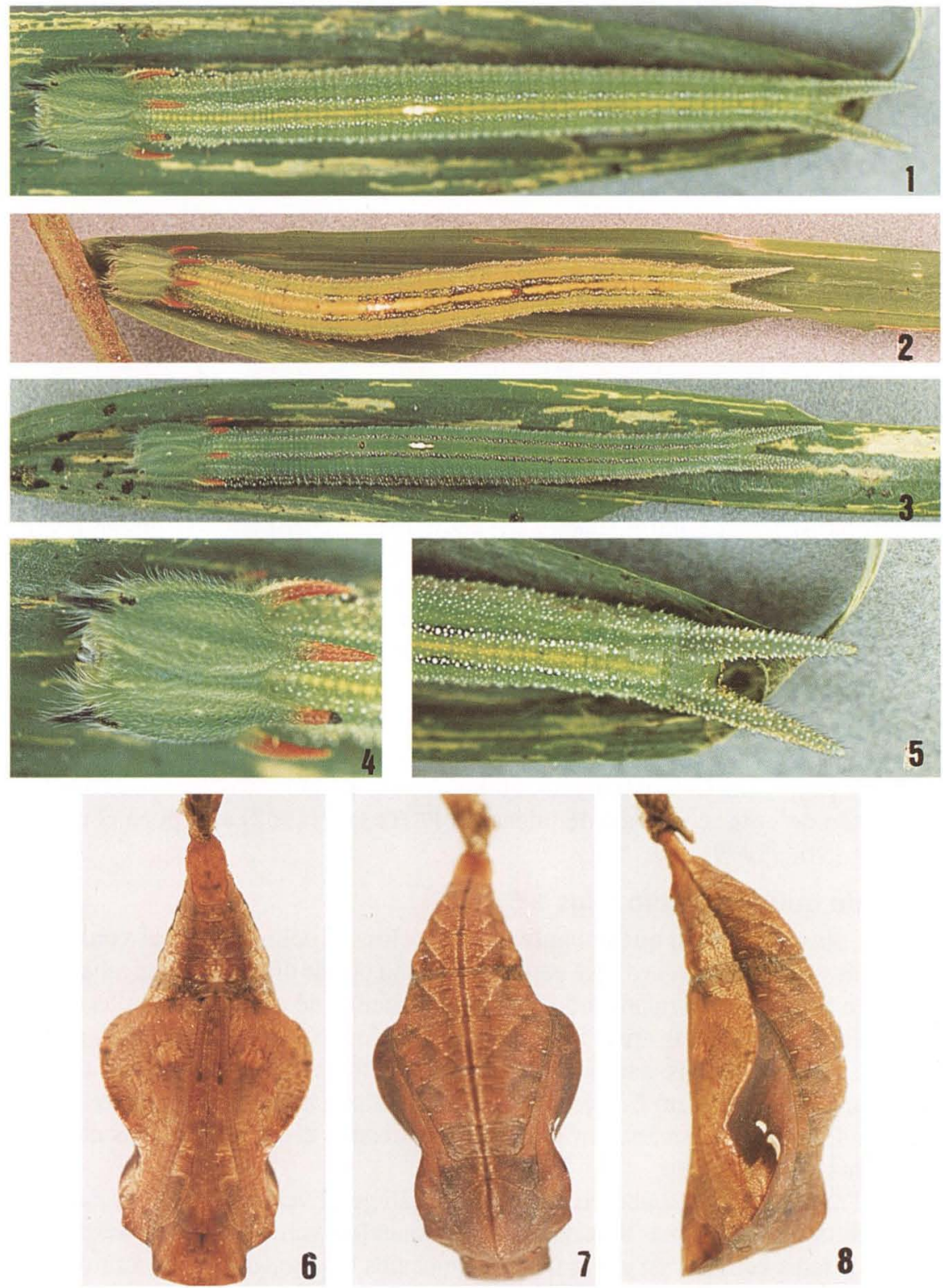

Figs 1-8. Dasyophthalma rusina rusina. (1-5) Larvas de quinto estádio: (1-3) vista dorsal; (4) cabeça, vista anterior; (5) projeções da placa suranal, vista dorsal. (6-8) Pupa: (6) vista anterior; (7) vista posterior; (8) vista lateral. 
pouco mais larga que a faixa dorsal e contornada por pontos ferrugíneos. Esta faixa pode estar ausente, em alguns exemplares (Fig. 3) ou ainda margeada por linha de pontos pretos (Fig. 2). Faixa subdorsal também verde, pouco acinzentada. Faixa espiracular ferrugínea como nos escolos, exceto nos segmentos torácicos onde é cinza. Peritrema dos espiráculos, ferrugem. Faixas supra e infraespiracular verde claro pouco amarelado. Projeções da placa suranal na mesma cor do tegumento, os pináculos são maiores que do tórax e abdome e cônicos.

As larvas passam para avermelhado quando próximo do período de empupar, e assim permanecem por aproximadamente dois dias.

Planta hospedeira: alimentam-se de folhas de Geonoma schottiana Martius (Arecaceae), normalmente no início da manhã e no final da tarde e repousam isoladamente sob as folhas, na nervura central, próximas à base das mesmas durante grande parte do dia. Não foi possivel testar a aceitação de folhas de bambú como citado por BöNNINGHAUSEN (1896). Foram testadas outras espécies de Arecaceae sem sucesso.

Atingem um comprimento máximo de 8 centímetros, incluindo as projeções da placa suranal.

\section{Pupa (Figs 6-8)}

Coloração geral castanho avermelhado, com matizes claras e escuras dos mesmos tons.

Ventralmente, cabeça, tórax e abdome, mais claros e com vários pontos em amarelo intenso. Antenas, pernas e asas com contorno em castanho. Dorsalmente mais escura e com nuances em ferrugem. A linha médio-dorsal é fortemente marcada por faixa castanho-escura, como também a região das tecas alares. Nestas, duas manchas em amarelo intenso correspondem em posição e tamanho àquelas citadas para Caligo beltrao Illiger, 1801 (CASAGRANDE 1979) e Caligo martia (Godart, [1824]) (CASAGRANDE \& MiElKe 2000). Abdome com linhas oblíquas de cor escura como citadas por YounG \& MUYSHONDT (1985) para Caligo atreus (Kollar, 1850) e Caligo memnon (C. Felder \& R. Felder, 1867), e para Caligo martia (Godart, [1824]) por CASAGRANDE \& MIELKE (2000). O comprimento das pupas variou entre 3 e $3,2 \mathrm{~cm}$ e a maior largura entre 1,8 e $2 \mathrm{~cm}$.

Este estágio tem uma duração média de 30 dias, com as larvas de quinto estádio empupando em dezembro e os adultos (Figs 9 e 10) emergindo em janeiro, sendo a espécie univoltina.

AGRADECIMENTO. Ao Prof. Dr. Armando Cervi do Departamento de Botânica da Universidade Federal do Paraná pela identificação da planta hospedeira.

\section{REFERÊNCIAS BIBLIOGRÁFICAS}

Bönninghausen, V. von. 1896. Beitrag zur Kenntnis der Lepidopteren-Fauna von Rio de Janeiro. Verhandl. Ver. Naturw. Unterh. Hamburg 9: 19-41.

Casagrande, M.M. 1979. Sobre Caligo beltrao (Illiger). I: Taxonomia, Biologia, Morfologia das Fases Imaturas e Distribuições Espacial e Temporal (Lepidoptera, Satyridae, Brassolinae). Rev. Brasil. Biol. 39 (1): 173-193.

CASAgrande, M.M. \& O.H.H. MielKe. 2000. Larva de quinto estádio e pupa de Caligo martia (Godart)

(Lepidoptera, Nymphalidae, Brassolinae). Revta bras. Zool. 17 (1): 75-79. 

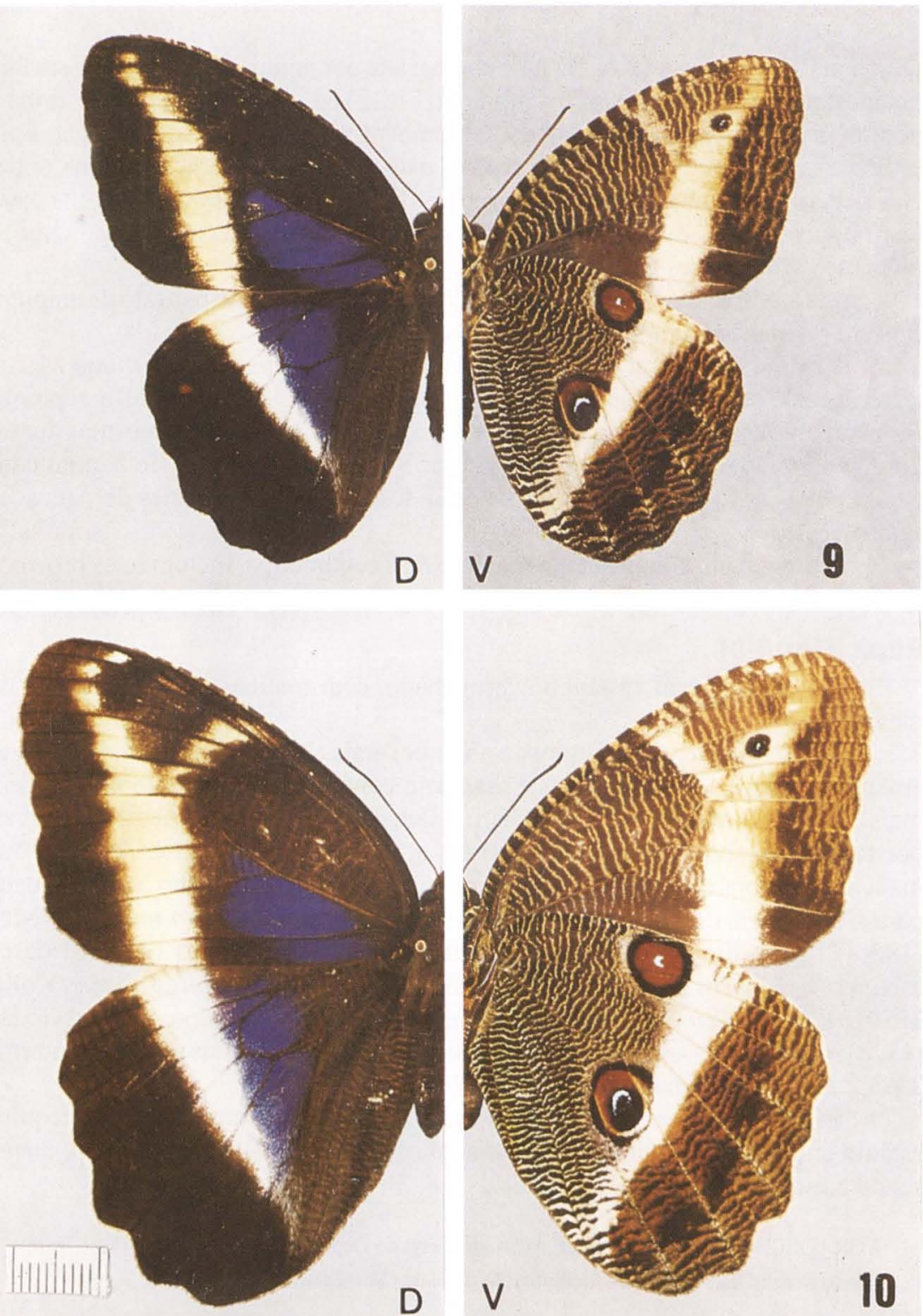

Figs 9-10. Dasyophthalma rusina rusina, vistas dorsal e ventral. (9) Macho; (10) fêmea.

PEterson, A. 1962. Larvae of Insects. An Introduction to Neartic Species. Part. I Lepidoptera and

Plant Infesting Hymenoptera. Ann Arbor, Edwards Brothers, Inc., 315p.

YonG, A.M. \& A. MuYshondt. 1985. Notes on Caligo meminon Felder and Caligo atreus Kollar. (Lepidoptera: Nymphalidae: Brassolinae) in Costa Rica and El Salvador. Jour. Res. Lep. 24 (2): 154-175.

Recebido em 31.III. 1999; aceito em 14.IV.2000. 